\title{
Bitcoin Fiyatlarındaki Değişimin Markov Rejim Değişim Modeli ile Analizi (An Analysis of Bitcoin Prices with The Markov Regime Switching Model)
}

\author{
Mustafa Can SAMIRKAŞ (iD) a \\ a Mersin Üniversitesi, Erdemli MYO, Finans, Bankacılık ve Sigortacılık Bölümü, Mersin, Türkiye mcsamirkas@gmail.com
}

\begin{tabular}{ll}
\hline MAKALE BILGISI & ÖZET \\
\hline Anahtar Kelimeler: & $\begin{array}{l}\text { Amaç - Çalışmada önemli fiyat dalgalanmalarına sahip kripto paralardan en yüksek işlem hacmine sahip } \\
\text { olan Bitcoin'in volatilite dinamiklerini tespit etmek için Bitcoin getirilerinin yükseliş/kazandıran ve } \\
\text { Kripto Para }\end{array}$ \\
Bitcoin & düşüş/kaybettiren rejimleri, rejim geçiş olasılıkları ve rejimde kalma sürelerinin tespit edilmesi
\end{tabular}

Markov Rejim Modeli

Gönderilme Tarihi 21 Ocak 2021

Revizyon Tarihi 5 Mart 2021 Kabul Tarihi 25 Mart 2021

Makale Kategorisi: Araştırma Makalesi

$$
\text { amaçlanmıştır. }
$$

Yöntem - Çalışmada Bitcoin getirilerinin yükseliş/kazandıran ve düşüş/kaybettiren rejimleri, rejim geçiş olasılıkları ve rejimde kalma süreleri hem değişimlerin hem de rejim geçiş olasılıklarının hesaplanmasına imkan veren Markov Rejim Değişim Modeli kullanılmıştır.

Bulgular - Çalışma kapsamında çalışmaya konu periyotta Bitcoin getiri serisi için en uygun modelin üç rejimli MSIH(3)-AR(1) modeli olduğu tespit edilmiştir. Modele ilişkin analizler yapıldığında ise söz konusu modelin doğrusal modele göre daha güçlü sonuçlar verdiği görülmektedir. Üç rejimden oluşan modelde katsayısı negatif olan rejim 1 daralma rejimi dönemini, katsayıları pozitif olan rejim 2 geçiş ve rejim 3 ise genişleme rejimi dönemini göstermektedir. Bitcoin getiri serisinin bir rejimdeyken bir sonraki dönemde aynı rejimde kalma olasılıkları yüksek iken bir sonraki dönemde özellikle rejim 1'den diğer rejimlere, diğer rejimlerden ise rejim 1'e geçiş olasılıklarının düşük olduğu tespit edilmiştir.

Tartışma - Çalışma kapsamında ele alınan dönem için Bitcoin getirilerinin rejim kalıcılığının yüksek olduğu tespit edilmiştir. Bu bağlamda yatırımcıların, Bitcoin getirilerinin incelenen dönemde hangi rejimde olduğunu bilmesi durumunda, bir sonraki dönemde bu rejimde kalma olasılığını tahminini yaparak yatırım kararını buna göre verme imkanı bulunmaktadır. Bununla birlikte ortalama rejimlerde kalma sürelerinin düşük olduğu göz önüne alındığında özellikle Bitcoin'i portföylerinde bulunduran aktif yatırımcıların sürekli olarak bu aracın rejim değişimlerini takip etmesi durumunda portföylerinin faydasını arttırma imkanı yakalayacağı görülmektedir.

\section{ARTICLE INFO}

\section{ABSTRACT}

\section{Keywords:}

Crypto currencies

Bitcoin

Markov Regime Switching Model

Received 21 January 2021

Revised 5 March 2021

Accepted 25 March 2021

Article Classification:

Research Article
Purpose - In the study, it is aimed to find the rising / gaining and falling / losing regimes, regime transition possibilities and duration of stay in the regime to determine the volatility dynamics of Bitcoin, which has the highest trade volume among crypto currencies.

Design/methodology/approach - In the study, the rising / gaining and falling / losing regimes, regime transition possibilities and duration of stay in the regime were determined by the Markov Regime Switching Model, which allows both changes and regime transition probabilities to be calculated.

Findings - In the study, for the study period it has been determined that the most suitable model for the Bitcoin return series is the three-regime MSIH (3) -AR (1) model which gives stronger results than the linear model. In the model consisting of three regimes, regime 1 with a negative coefficient indicates the contraction regime period, while regime 2 with positive coefficients indicates the transition and regime 3 the expansion regime period. It has been determined that while the Bitcoin returns series is in a regime, the probability of staying in the same regime for the next period is high, the possibility of transition from regime 1 to other regimes and from other regimes to regime 1 is low for the next period.

Discussion - It has been determined that the regime persistence of Bitcoin returns is high for the period under study. In this context, if investors know the regime of Bitcoin returns in the current period, they have the opportunity to estimate the probability of staying in this regime and make their investment decision according to this information. However, considering that average duration of stay in the regimes is low, it is seen that active investors who keep Bitcoin in their portfolios will have the opportunity to increase the utility of their portfolios if they constantly follow the regime changes of this tool. 


\section{GİRISs}

Yeni bir teknoloji olarak Blockchain, Bitcoin gibi kripto para birimlerini ve birçok uygulamayı ülke ekonomilerine entegre etmeye başlamıştır. Merkezi bir otoriteye bağlı olmayan geleneksel para birimlerinden çok farklı olan bu dijital paralar kriptografik olarak güvenceye alınmakta ve uluslararası dolaşımında herhangi bir engel bulunmamaktadır. Klasik para birimlerine kıyasla birçok avantajı bulunan bu paralar birçok ekonomik birim için cazip hale gelmiş ve sadece finansal piyasalar için değil reel piyasalar için de ilgili duyulan bir araç haline gelmiştir. Nitekim Bitcoin ve 2021 yılı başı itibariyle sayları sekiz bini aşan diğer kripto para birimleri birçok piyasada işlem görmeye başlamış özellikle son yıllarda yatırımcıların ilgisini çeken en önemli yatırım araçlarından birisi olarak kabul edilmeye başlanmıştır (coinmarketcap.com, 04.01.2021). Kripto para piyasasının işleyişi, geleneksel finansal piyasaların işleyişinden farklıdır. Bu durum yatırımcıların ve medyanın yanında araştırmacıların da ilgisini bu piyasaya yönlendirmesine neden olmuş ve Bitcoin piyasasını inceleyen akademik çalışmaların sayısının artmasını sağlamıştır (Evci, 2020:54).

Şüphesiz kripto paralara ilginin artmasına neden olan para birimi, öncü ve piyasa kapitalizasyonun önemli bir kısmına sahip olan Bitcoin'dir. 2009 yılında piyasaya çıktığında oldukça düşük fiyatlarla işlem gören bu yeni finansal aracın fiyatları geçen süreç içinde finansal araçlar için rekor denebilecek seviyelere ulaşmıştır. Bununla birlikle son yıllarda Japonya, Güney Kore ve Almanya gibi bazı ülkeler Bitcoin'i yasal ödeme aracı olarak benimsemiş, Microsoft, Dell, Enercity, Yandex, Ulmart ve SCAN gibi çok sayıda büyük şirket ise Bitcoin ile ticaret yapmaya başlamıştır (Ma vd. 2020:1277). Bu durum Bitcoin ve birçok kripto paranın kısa sürede ülkelerin ekonomilerine ve ticari hayatlarına entegre olmaya başladığını göstermekte olup, Bitcoin'in geçici bir finansal teknolojiden ziyade gelecekte de yaygın olarak kullanılacak bir finansal araç olduğunu göstermektedir.

Bu yeni yatırım araçlarındaki fiyatlar önemli şekilde dalgalanmakta ve yüksek karlara ya da yüksek zararlara neden olabilmektedir. Bu nedenle kripto para yatırımcılarının kripto paranın bu dinamiklerini anlamalarına, bunları yöneterek portföy seçimi yapmalarına ve portföylerini optimize etmelerine imkan sağlayacak araçlara, süreçlere ve yöntemlere ihtiyaçları vardır. Yatırımcılar için yatırım yapacakları araçların gelecekteki değişimlerini tahmin etmekte kullanacakları güvenilir bir modelin olması öncelikli ilgi alanlarından birisidir.

Birçok finansal yatırım aracı gibi kripto paraların getirileri de zaman içinde bazı rejim değişiklikleri gösterebilmekte ve rejim değişim modellerinin kullanımıyla bu rejimlerin volatilite dinamikleri tespit edilebilmektedir. Çalışmada önemli fiyat dalgalanmalarına sahip kripto paralardan en yüksek işlem hacmine sahip olan Bitcoin'in volatilite dinamiklerini tespit etmek için Bitcoin getirilerinin yükseliş/kazandıran ve düşüş/kaybettiren rejimleri, rejim geçiş olasılıkları ve rejimde kalma sürelerinin tespit edilmesi amaçlanmıştır. Bu bağlamda çalışmada Bitcoin getirilerinin kaç rejim dönemine sahip olduğu, bu rejimlerdeyken bir sonraki dönemde diğer bir rejime geçme olasılıklarının ne olduğu ve bir rejimde kalma süresinin ortalama olarak ne kadar olduğunu tespit etmek amacıyla hem değişimlerin hem de rejim geçiş olasılıklarının hesaplanmasına imkan veren Markov Rejim Değişim Modeli kullanılmıştır.

\section{LİTERATÜR}

Markov Analizi, geçmişteki durumlardan bağımsız olarak mevcut duruma bağlı kalan sürecin gelecekte nasıl bir gelişim göstereceğini içeren olasılıkları bulunduran ve belirsiz süreçler içeren durumlar hakkında karar almayı amaçlayan bir teknik olarak kullanılmaktadır. Markov analizi, finans, iktisat, üretim, malzeme yönetimi, pazarlama, eğitim, klimatoloji gibi birçok uygulama alanı bulunmaktadır (Dadaloğlu, 2018:3). Markov sürecinin en büyük özelliği, olasılıkların geçmiş ve şu andaki değerlerinden faydalanılarak gelecekteki olasılık değerlerinin hesaplanmasına izin vermesidir. Bunu yaparken de geçmişteki olasılıklardan bağımsız bir şekilde mevcut sürenin değerlerine bağlı kalarak gelecekteki değerin nasıl değişeceğini hesaplar. Yani t dönemdeki olasılıkları hesaplarken sadece t-1dönemin değerlerinden, $t-1$ dönemin değerleri için de $t-2$ dönemin değerlerinden faydalanır (Güleşce, 2019:15).

Markov Rejim Değişim Modeli finansal piyasalarda rejim değişim dönemlerini belirlemek, finansal varlıkların oynaklıklarını tahmin etmek, döviz kurlarının, enflasyonun ve faizlerin tahmini ve modellemeleri ile finansal krizlerin öngörülebilirliğini tahmin etmek gibi finansın birçok alanında kullanılmaktadır. 
Literatürde kripto para piyasasını konu alan ve Markov rejim değişim modeline dayanan sınırlı sayıda çalışmaya bulunmakla birlikte, diğer finansal yatırım araçlarını, borsa endekslerini, altın piyasası ve petrol piyasalarını konu alan çalışmalar da bulunmaktadır.

Markov rejim prosedürünü kripto paralar üzerinden uygulayan öncü çalışmalar Moln'ar ve Thies (2018)'in kripto paralar için önerdiği yedi rejimli Markov Modelini önerdiği, Chappell (2018)'ın beş rejimli Markov Rejim Modelini önerdiği çalışmalardır. Bu çalışmaları takiben ARCH temelli ve yeni geliştirilen Markov Rejim Modelli ya da doğrusal modellerle kıyaslama yapılan çalışmalar da yapılmıştır. Bu çalışmalardan bazılarını aşağıdaki gibi özetlemek mümkündür.

Maupin (2019) çalışmasında Bitcoin, Ethereum, Ripple ve Litecoin serileri için kripto para birimi fiyatlarının gelecekteki fiyatların tahmininde hangi modelin daha iyi sonuçlar verdiğini tespit etmek amaciyla AR(p), MSAR (p), VAR (p) ve MSVAR (p) olmak üzere dört farklı zaman serisi modelini uygulamıştır. Seçilen para birimleri için Markov Rejim modellerinin daha verimli sonuçlar verdiğini tespit etmiştir. Bununla birlikte kripto paralarda volatilitelerin yüksek olması ve ömrünün kısa olmasının spekülatörler açısından sorun yarattığı savına karşı, Markov Rejim modeli uygulanarak bugünün rejiminin bilinmesinin yarının rejiminin geçiş matrisine bağlı olarak tahmin edilebileceği sonucuna varmıştır.

Ardia vd (2019) çalışmalarında 18.08.2011-03.03.2018 periyodunda Bitcoin volatilite dinamiklerini iki rejimli MSGARCH(Markov Rejim Değişim GARCH) modeli ile analiz etmişlerdir. Çalışmaya konu periyotta hem yüksek volatilite dönemlerinde hem de düşük volatilite dönemlerinde iki rejimli MSGARCH modelinin en iyi performansı gösterdiği sonucuna varmışlardır. Bununla birlikte bir dönem sonrası için riske maruz değer tahminlerinde Markov Değişim Süreçlerinin standart tek rejimli GARCH modellerine göre açıkça daha başarılı olduğunu tespit emişlerdir.

Söylemez ve Yılmaz Türkmen (2019) çalışmalarında Bitcoin getirilerinin volatilite dinamiklerini MSGARCH modeli ile tespit etmeye çalışmışlardır. 29.04.2013-17.04.2019 dönemini için Bitcoinin günlük getirilerini dikkate alan çalışmada Bitcoin getirilerinin üç rejimli olduğu 1. Rejimde sabit katsayının negatif olduğu, diğer iki rejimde ise pozitif olduğu tespit edilmiştir. Bu bağlamda çalışmaya konu periyot için Bitcoin getirilerinin negatif getiri, durağan ve pozitif getiri olmak üzere üç farklı rejimde geçişken oldukları ortaya konulmuştur.

Mba ve Mwambi (2020) çalışmalarında, portföy seçiminde iki durumlu MSCOGARCH Markov rejim modeli ile tek rejimli COGARCH modelini karşılaştırmıştır ve literatürle uyumlu olarak MSCOGARCH modelinin beklenen risk açığı açısından tek rejimli COGARCH modelinden daha iyi performans gösterdiği sonucuna ulaşmışlardır.

Ma vd. (2020) çalışmalarında karma veri örnekleme modeliyle geliştirdikleri bir Markov Rejim modelinin (MRS-MIADS) Bitcoin'in gerçekleşen varyansının tahmin gücünü arttırıp arttırmayacağını sınamışlardır. Çalışma sonucunda önerilen MRS-MIADS modelin Bitcoin'in gerçeleşen varyansının tahmin edilmesinde 2 haftalık ve 1 aylık ufuk tahminler için istatistiksel olarak önemli gelişmeler gösterdiği tespit edilmiştir.

Koki vd. (2020) çalışmalarında, Bitcoin, Etherium ve Ripple getirilerinin rejim dinamiklerini tespit etmek için çok rejimli çeşitli Saklı Markov modellerini denemişlerdir. Çalışma sonucunda dört rejimli homojen olmayan Saklı Markov (NHHM) modelinin üç kripto para birimi için de diğer tim modellerden daha iyi tahmin performansına sahip olduğu tespit edilmiştir.

Rojas ve Coronado (2020) çalışmalarında 19.12.2011-07.08.2017 tarihleri arasında MS-GARCH modeli ile Bitcoin getirilerinin volatilite dinamiklerini tespit etmeye çalışmışlardır. Model volatilitenin yüksek ve volatilitenin düşük olduğu iki rejimli olarak kurulmuş olup, yüksek volatilite rejiminin süresini ve nedenlerini tespit etmeye çalışmışlardır. Çalışma sonucunda toplamda 28 alt dönemde yüksek volatilitenin olduğu en yüksek dönemin ise 2013 yılında olduğu tespit edilmiştir. Volatilitedeki bu hızlı değişimlerin Bitcoin fiyatlarının haberlere karşı hızlı tepki vermesinden, haberlere hızlı tepki vermenin ise bu aracın bir bilgisayar algoritmasından oluşmasından kaynaklı olabileceği bununla birlikte piyasa hacminin de getirilerdeki volatilitenin kaynağı olabileceği ifade edilmiştir. 


\section{YÖNTEM}

Çalışmada Bitcoin getiri serisinin rejim değişimlerini, rejim değişim olasılıklarını ve rejimlerde kalma sürelerini tespit etmek amacıyla Markov Rejim Değişim modeli kullanılmıştır. Markov Analizi tekniği, A.A. Markov tarafından 1905 yılında yapılan, gaz moleküllerinin yapısını ve davranışlarını matematiksel olarak betimleme denemesine dayanan bir teknik olarak ortaya çıkmıştır. Markov sürecinin ilk doğru matematiksel yapısı N. Wiener tarafından 1923 yılında kurulmuştur. Markov süreçlerinin genel teorisi ise 1930 ve 1940 yıllarında A.N. Kolmogoron, W. Feller, W. Doeblin, P. Levy, J.L. Doob vd. geliştirilmiştir (Eroğlu,2019:275). 1989 yılında Hamilton tarafından Markov zincirine dayalı olarak geliştirilen MS-AR(p) modeline Engel (1994), Diebold, Lee ve Winbach (1994), Hamilton (1996), Kim ve Nelson (1998), Krolzing (1997, 1998, 2000, 2001) ve Chen (2006) çalışmalarıyla önemli katkılar sağlamıştır.

Markov Rejim Değişim modeli, lineer zaman serilerinden farklı olarak değişik alt dönemlerde farklı özellikler gösteren lineer olmayan bir yapıya sahiptir. Gösterge fonksiyonu olarak simgelenen bir değişkenle en az iki rejimden oluşan süreç, rejim değişkeni olarak tanımlanan ve kukla değişken gibi hareket eden bir değişkenle birleştirilir. Böylelikle, farklı özelliğe sahip (yükseliş/genişleme/kazandıran-düşüuş/daralma/kaybettiren gibi) dönemleri ayrı ayrı değerlendirilme imkanı bulunmaktadır(Evci, 2016:69).

Markov Rejim Modelini genel olarak aşağıdaki gibi tanımlamak mümkündür.

$$
Y_{t}=S_{t} \mu_{1}+\left(1-S_{t}\right) \mu_{2}+\varepsilon_{t}
$$

Burada $s_{t}$ gözlenemeyen durum değişkenini ifade etmektedir ve iki durumlu rejimlerde 0 ve 1 değerlerini alan durum değişkenidir.

$$
\begin{aligned}
& S_{t}=1 \Rightarrow Y_{t}=\mu_{1}+\varepsilon_{t} \\
& S_{t}=0 \Rightarrow Y_{t}=\mu_{2}+\varepsilon_{t} \\
& S_{t}, 1,2, \ldots ., k \text { gibi iki veya daha fazla değer ald } \breve{g} \iota n d a \Rightarrow Y_{t}=\mu_{s_{t}}+\varepsilon_{t}
\end{aligned}
$$

Tek değişkenli ve 2 rejimli Markov Rejim Değişim modeli, MS-AR(p) modeline genişletilebilmektedir.

$$
Y_{t}=c\left(S_{t}\right)+\beta_{1}\left(S_{t}\right) Y_{t-1}+\cdots+\beta_{p}\left(S_{t}\right) Y_{t-p}+\left(S_{t}\right) u_{t}
$$

Modelde $S_{t}$, gözlenemeyen durum değişkenlerini ifade ederken, hata terimlerinin 0 ortalama ve 1 varyansla normal dağıldığı varsayılmaktadır. MS-AR(p) modelleriyle serinin içinde bulunduğu sürecin rejimini bir sonraki dönemde bu rejimde kalma ve/veya diğer rejime geçme olasılıkları ile bu rejimlerde ortalama olarak ne kadar süre kaldıkları da tespit edilebilmektedir. $P_{i j}$, rejimler arası sabit geçiş olasılıkları olarak adlandırılmakta ve iki durumlu rejimler için aşağıdaki gibi gösterilebilmektedir.

$$
P_{i j}=\left[\begin{array}{ll}
P_{11} & P_{12} \\
P_{21} & P_{22}
\end{array}\right]
$$

$P_{i j}$ matrisindeki her bir değer,

$$
P\left(S_{t=j} / S_{t-1=i}\right)=P_{i j} \quad(i, j=1,2)
$$

olarak koşullu olasılık biçiminde gösterilebilir. Bu gösterime göre, $P_{11}$, süreç birinci rejimde bulunurken bir dönem sonra tekrardan birinci rejimde kalma olasılığını gösterirken, $P_{12}$, süreç birinci rejimde bulunurken bir dönem sonra ikinci rejime geçme olasıllğını göstermektedir. Bununla birlikte $P_{22}$, süreç ikinci rejimde bulunurken bir dönem sonra tekrardan ikinci rejimde kalma olasılığını, $P_{21}$ ise süreç ikinci rejimde bulunurken bir dönem sonra birinci rejime geçme olasılığını göstermektedir.

Sabit geçiş olasılıklarıyla serinin rejimde kalma süreleri de belirlenebilmekte olup, serinin birinci rejimde bekleme süresi, 


$$
\frac{1}{1-P_{11}}
$$

ikinci rejimde bekleme süresi ise,

$$
\frac{1}{1-P_{22}}
$$

şeklinde formüle edilebilmektedir. Bunun sonucunda serilerin her bir rejimde ortalama olarak ne kadar süre kalacağ1 tespit edilebilmektedir.

Yeni bir finansal teknoloji ürünü olarak 2009 yılında piyasaya çıkan kripto paraların ilki ve hala en büyük piyasa işlem hacmine sahip kriptopara Bitcoin'dir. Bitcoin' in ardından birçok yeni kripto para birimi hızlı bir şekilde finansal piyasalara giriş yapmıştır (Gültekin ve Bulut, 2016: 82). Çalışma kapsamında Bitcoin fiyatlarından elde edilen logaritmik getiriler kullanılmış olup, çalışmanın periyodu da göreli olarak kripto para piyasasındaki rekabetin ve volatilitenin arttı̆̆ 2016 yılından başlamıştır.

Markov Rejim Değişim modeli, serilerin durağan olduğunu ve doğrusal olmadığını varsaymaktadır. Bu nedenle ilk önce serinin durağanlığı literatürde yaygın olarak kullanılan ADF (Augmented Dicket Fuller) ve PP (Philips Perron) birim kök test testleriyle sınanmıştır. Her iki testin de sıfır hipotezi serinin birim köke sahip olduğunu ileri sürmektedir. Markov Rejim Değişim modelinin doğru sonuçlar vermesi için serinin durağan olması gerekmekte olup, birim köke sahip seriler ise durağanlaştırılarak analize konu edilmektedir.

Serlerin doğrusallı̆̆ı ise yine literatürde yaygın olarak kullanılan Brock, Dechert ve Scheinkman (1986) tarafından geliştirilen BDS testi ile sınanmıştır. Portmanto karakterli bir test olan BDS testinin sıfır hipotezi, rassal olmayan dinamikleri tespit etmek amacı ile verinin bağımsız benzer dağılıma sahip olup olmadığı tezini içermektedir. Yani serinin doğrusallığından elde edilen hata terimlerinin bağımsız özdeş dağıldı̆̆ı varsayımına karşılık alternatif hipotezde temel olarak doğrusal olmayanlığı test edilmektedir (Sezgin Alp ve Kırkbeşoğlu, 2015:253; Bayat vd. 2013:84). Durağan ve doğrusal olmayan seriler Markov Rejim Değişim Modeliyle yapılan sınamalarda kullanılarak. Rejim değişimleri, değişim olasılıkları ve rejimde kalma süreleri tespit edilebilmektedir.

\section{VERİ SETİ ve BULGULAR}

Çalışmada kullanılan Bitcoin fiyat serisine, investing.com'dan ulaşılmıştır. Çalışmanın veri setini, 24.08 .2016 - 21.12.2020 tarihleri arasındaki günlük dolar cinsinden Bitcoin kapanış fiyatları oluşturmaktadır. Bitcoin fiyatlarına ilişkin logaritmik getiriler $\log (\mathrm{Pt} / \mathrm{Pt}-1)$ formülü kullanılarak hesaplanmıştır. Ele alınan dönem için Bitcoin getiri serisine (BTC) ilişkin zaman yolu grafiği aşağıdaki gibidir.

BTC

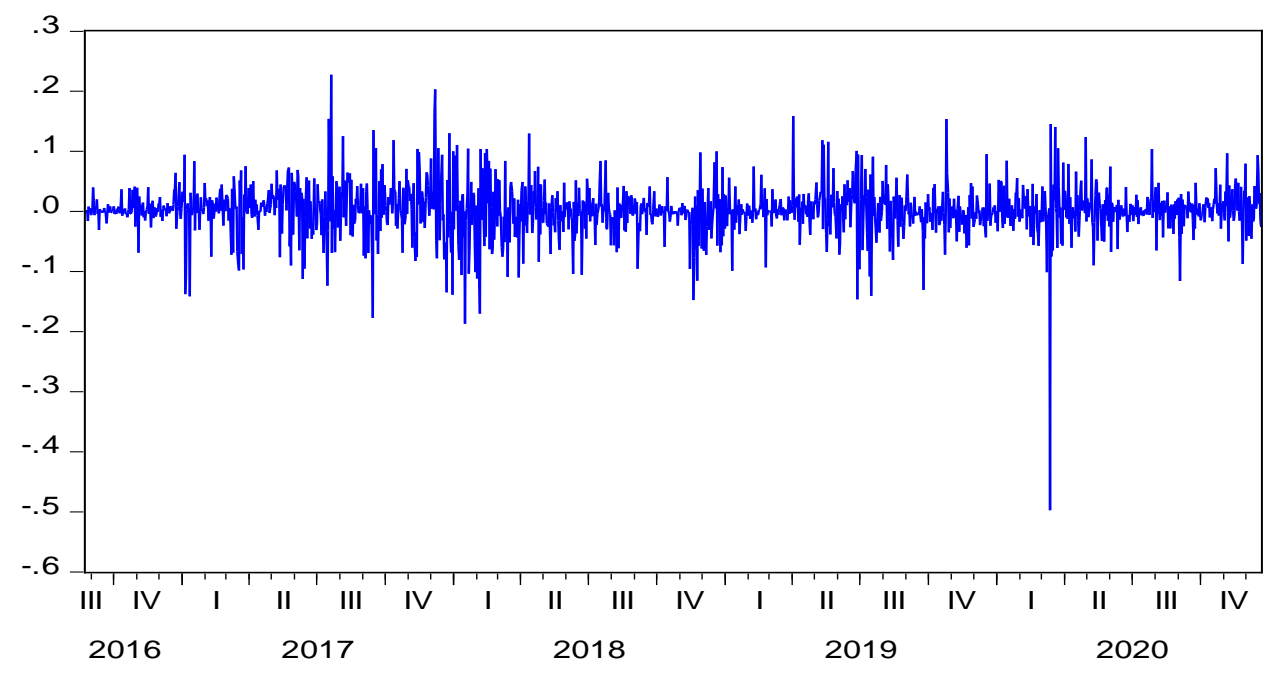

Şekil 1. Bitcoin Getiri Serisi 
M. C. Samırkaş 13/1 (2021) 813-824

Tablo 1'de Bitcoin' in logaritmik getiri serisinin tanımlayıcı istatistikleri verilmiş olup, ilgili dönemde Bitcoin'in logaritmik ortalama getirisinin pozitif olduğu, serinin sola çarpık ve aşırı basık bir dağılım gösterdiği görülmektedir. Bununla birlikte Jarque-Bera test istatistiği serilerin normal dağılım göstermediği sonucunu vermektedir.

Tablo 1.Tanımlayıc İstatistikler

\begin{tabular}{|c|c|c|c|c|c|c|c|c|c|}
\hline Değişken & Gözlem & Ortalama & Medyan & Maksimum & Minimum & $\begin{array}{c}\text { Standart } \\
\text { Sapma }\end{array}$ & Çarpıklık & $\begin{array}{c}\text { Basılklık } \\
\text { Jarque- } \\
\text { Bera }\end{array}$ \\
\hline BTC & 1580 & 0.002326 & 0.002345 & 0.227602 & -0.497278 & 0.041449 & -1.103031 & 18.89468 & $\begin{array}{c}16952.57 \\
(0.0000)^{*}\end{array}$ \\
\hline
\end{tabular}

* Parantez içindeki değer olasılık (probability) değerini göstermektedir.

BTC serisinin durağanlığı literatürde yaygın olarak kullanılan ADF (Augmented Dickey-Fullar) ve PP (Phillips Perron) birim kök testleriyle sınanmıştır. Her iki test sonucuna göre de serinin düzeyde durağan olduğu tespit edilmiştir.

Tablo 2.ADF ve PP Birim Kök Testi Sonuçları

\begin{tabular}{|l|c|c|c|c|c|}
\hline \multicolumn{2}{|c|}{} & \multicolumn{2}{c|}{$\begin{array}{c}\text { Augmented Dickey-Fuller } \\
\text { (ADF) test istatistiği }\end{array}$} & \multicolumn{2}{c|}{$\begin{array}{c}\text { Philips-Peron } \\
\text { (PP) test istatistiği }\end{array}$} \\
\hline Değişken & Seviye & Sabit & Trend ve Sabit & Sabit & Trend ve Sabit \\
\hline \multirow{2}{*}{ BTC } & \multirow{2}{*}{ Düzey } & -41.78695 & -41.78730 & -41.73433 & -41.73463 \\
& & $(0.0000)^{*}$ & $(0.0000)^{*}$ & $(0.0000)^{*}$ & $(0.0000)^{*}$ \\
\hline
\end{tabular}

* Parantez içindeki olasılık (probability) değeri \%1 seviyesinde istatistiksel olarak anlamlılığı göstermektedir. Durağan olduğu tespit edilen BTC serisinin doğrusallığı BDS (Brock, Dechert ve Scheinkman(1986)) testi ile sınanmışır. BDS test sonuçları Tablo 3'deki gibidir.

Tablo 3.BTC Getiri Serisinin BDS Test Sonuçları

\begin{tabular}{|c|c|c|c|c|}
\hline Boyut & BDS İstatistiği & Standart Hata & z-İstatistiği & Olasılık (Prob.) \\
\hline 2 & 0.017994 & 0.002689 & 6.691870 & 0.0000 \\
\hline 3 & 0.037796 & 0.004282 & 8.826905 & 0.0000 \\
\hline 4 & 0.052887 & 0.005111 & 10.34782 & 0.0000 \\
\hline 5 & 0.063500 & 0.005340 & 11.89042 & 0.0000 \\
\hline 6 & 0.068651 & 0.005164 & 13.29485 & 0.0000 \\
\hline
\end{tabular}

Tablo 3'te görüldüğ̈̈ üzere ele alınan tüm boyutlarda BDS test istatistiğinin "seri doğrusaldır" şeklinde kurulan sıfır hipotezi reddedilmiştir. Bu bağlamda ele alınan dönem içinde istatistiksel olarak doğrusal olmadığ 1 kabul edilen BTC getiri serisinin analizinde doğrusal olmayan zaman serisi modellerinin kullanılmasının daha güçlü sonuçlar vermesi beklenmektedir.

Bu aşamadan sonra BTC serisinin analizinde doğrusal olmayan zaman serisi yöntemlerinden biri olan Markov rejim değişim modeli kullanılmıştır. Getiri serisi için en uygun Markov rejim değişim modelinin belirlenmesinde, Akaike (AIC), Shwartz (SC), Hannan Queen (HQ) bilgi kriterleri ve log-olabilirlik oranından yararlanılmıştır.

Tablo 4.Bilgi Kriterlerine Göre Uygun Model Seçimi

\begin{tabular}{|c|c|c|c|c|}
\hline & AIC & HQ & SIC & Log-Olabilirlik Oranı \\
\hline MSIH(2)-AR (0) & -3.880342 & -3.872772 & -3.859968 & 3071.471 \\
\hline MSIH(2)-AR (1) & -3.883862 & -3.875025 & -3.860080 & 3073.309 \\
\hline MSIH(2)-AR (2) & -3.882454 & -3.872349 & -3.855261 & 3071.256 \\
\hline MSIH(2)-AR (3) & -3.881200 & -3.869826 & -3.850592 & 3069.326 \\
\hline MSIH(2)-AR (4) & -3.878572 & -3.865927 & -3.844545 & 3066.315 \\
\hline
\end{tabular}


M. C. Samırkaş 13/1 (2021) 813-824

\begin{tabular}{|c|c|c|c|c|}
\hline MSIH(3)-AR (0) & -3.952758 & -3.937617 & -3.912009 & 3134.678 \\
\hline MSIH(3)-AR (1) & $-3.957793^{*}$ & $-3.941381^{*}$ & $-3.913626^{*}$ & $3137.677^{*}$ \\
\hline MSIH(3)-AR (2) & -3.955835 & -3.938151 & -3.908246 & 3135.154 \\
\hline MSIH(3)-AR (3) & -3.955753 & -3.936796 & -3.904739 & 3134.112 \\
\hline MSIH(3)-AR (4) & -3.955753 & -3.936796 & -3.904739 & 3134.112 \\
\hline
\end{tabular}

Tablo 4' de görüldüğg̈ üzere AIC, HQ ve SIC bilgi kriterlerine göre en küçük ve log-olabilirlik oranına göre en büyük değere sahip model, rejim ile birlikte sabit terimlerin (I) ve varyansın (H) değiştiği MSIH(3)-AR(1) modelidir.

Tablo 5.Bitcoin Getirisine İlişkin Sabit Geçiş Olasılıklı MS Modeli

\begin{tabular}{|c|c|c|c|c|}
\hline \multicolumn{5}{|c|}{ Bağımlı Değişken: BTC } \\
\hline Bağımsız Değişkenler & Katsayı & Standart Hata & Z-İstatistiği & Olasılık (Prob) \\
\hline \multicolumn{5}{|c|}{ Rejim 1} \\
\hline C & -0.000998 & 0.004083 & -0.244400 & 0.8069 \\
\hline SIGMA & -2.674032 & 0.067870 & -39.39907 & 0.0000 \\
\hline \multicolumn{5}{|c|}{ Rejim 2} \\
\hline C & 0.001643 & 0.000594 & 2.766988 & 0.0057 \\
\hline SIGMA & -4.658740 & 0.079595 & -58.53048 & 0.0000 \\
\hline \multicolumn{5}{|c|}{ Rejim 3} \\
\hline $\mathrm{C}$ & 0.004867 & 0.001630 & 2.985843 & 0.0028 \\
\hline SIGMA & -3.323094 & 0.058262 & -57.03722 & 0.0000 \\
\hline \multicolumn{5}{|c|}{ Ortak } \\
\hline BTC $(-1)$ & -0.085710 & 0.022012 & -3.893841 & 0.0001 \\
\hline \multicolumn{5}{|c|}{ Geçiş Matrisi Parametreleri } \\
\hline P11-C & 2.752229 & 0.474633 & 5.798645 & 0.0000 \\
\hline P12-C & -15.16553 & 1081.661 & -0.014021 & 0.9888 \\
\hline P21-C & -3.956640 & 2.161314 & -1.830664 & 0.0672 \\
\hline P22-C & 0.721293 & 0.266741 & 2.704101 & 0.0068 \\
\hline P31-C & -3.267357 & 0.498081 & -6.559890 & 0.0000 \\
\hline P32-C & -1.038087 & 0.420220 & -2.470343 & 0.0135 \\
\hline
\end{tabular}

*Box-Pierce testine göre "hata terimlerinde otokorelasyon yoktur" şeklinde kurulan sıfır hipotezi reddedilememiştir (kabul edilmiştir.)

BTC serisi için tahmin edilen MSIH(3)-AR(1) modeli ile doğrusal model arasında en uygun modeli belirlemek için LR ve Davies istatistikleri ile model seçim kriterlerinden yararlanılmıştır.

Tablo 6.Tahmin edilen Modelin Doğrusallık Analizi

\begin{tabular}{|l|r|}
\hline & Test İstatistiği \\
\hline LR Testi & 694.910 \\
\hline LR Testi Olasılık Değeri (Prob.) & 0,0000 \\
\hline DAVIES Testi Olasılık Değeri (Prob.) & 0,0000 \\
\hline
\end{tabular}

Tablo 6'da yer alan test sonuçları incelendiğinde, hem LR testine hem de Davies testine göre serinin doğrusal modellenmesi gerektiğini ileri süren sıfır hipotezi \%1 anlamlılık düzeyinde reddedilmiştir. Tablo $7^{\prime}$ de ise doğrusal ve doğrusal olmayan MSIH(3)-AR(1) modeline ait model seçim kriterleri verilmiştir.

Tablo 7. Bitcoin Getirileri için Doğrusal ve Doğrusal Olmayan Modele ait Bilgi Kriterleri

\begin{tabular}{|c|c|c|}
\hline & Doğrusal Model & $\begin{array}{c}\text { Doğrusal Olmayan } \\
\text { MSIH(3)-AR(1) Modeli }\end{array}$ \\
\hline AIC & -3.528129 & $-3.957793^{*}$ \\
\hline SIC & -3.517942 & $-3.913626^{*}$ \\
\hline HQ & -3.524343 & $-3.941381^{*}$ \\
\hline Log likelihood & 2790.222 & $3137.677^{*}$ \\
\hline
\end{tabular}


Yapılan analizler sonucunda gerek LR ve Davies test sonuçları gerekse AIC, SIC ve HQ bilgi kriterleri Bitcoin getiri serisi için yapılacak modellemede lineer olmayan modellerin kullanımının daha güçlü sonuçlar vereceğini ortaya koymuştur. Bu bağlamda Bitcoin getiri serisi için Tablo 5'te sonuçları özetlenen MSIH(3)AR(1) modeli uygun model olarak tanımlanmıştır. Uygun model olarak kabul edilen üç rejimli MSIH(3)-AR(1) modelinde ortalama getiri için hesaplanan sabit katsayı ve varyansın üç rejim için de farklı olduğu görülmektedir. Bununla birlikte hata terimlerinde otokorelasyon bulunmayan modelde üç rejim için de ortak bir parametre değeri bulunmuştur.

MSIH(3)-AR(1) modeli tahmin sonuçlarına göre; katsayısı negatif olan rejim 1 daralma rejimi dönemini, katsayıları pozitif olan rejim 2 geçiş ve rejim 3 ise genişleme rejimi dönemini göstermektedir. Birinci rejim, volatilitenin en yüksek olduğu ve getirilerin negatif olduğu rejimdir. En düşük volatiliteye sahip rejim geçiş rejimi olarak adlandırılan ikinci rejim olduğu, en yüksek getiriye sahip olan rejimin ise genişleme rejimi olarak adlandırılan üçüncü rejim olduğu görülmektedir. Bu sonuçlara göre; volatilitenin artmasıyla birlikte riskin de arttığ varsayımı altında, rejim 2 volatilitenin ve getirinin en düşük olduğu, bununla birlikte riskin de en az olduğu rejim olarak tanımlanabilir. Rejim 3 volatilitenin, getirinin ve riskin ikinci rejime göre daha yüksek olduğu, rejim 1 ise volatilitenin ve riskin en yüksek olduğu, bununla birlikte getirinin de negatif olduğu rejimdir.

MSIH(3)-AR(1) modeli ile serilerin mevcut rejim içinde ne kadar süreyle daralma, geçiş ve yükseliş döneminde bulunacağı ve modelin rejim geçiş olasılıkları tespit edilebilmektedir. BTC serisine ait Markov sabit geçiş olasılıkları matrisi Tablo 8'de gösterilmiştir.

Tablo 8.Rejim Olasılıkları Matrisi

\begin{tabular}{|c|c|c|c|c|}
\hline & Rejim 1 & Rejim 2 & Rejim 3 & Tüm Örneklem \\
\hline Rejim 1 & 0,94003900 & 0,00000002 & 0,05996100 & 1,00000000 \\
\hline Rejim 2 & 0,00621800 & 0,66870800 & 0,32507400 & 1,00000000 \\
\hline Rejim 3 & 0,02737100 & 0,25436100 & 0,71826800 & 1,00000000 \\
\hline
\end{tabular}

Modelin rejim geçiş olasılıkları incelendiğinde Bitcoin getiri serisi rejim 1'de iken tekrardan 1. rejimde kalma olasılığı yaklaşık \%94; rejim 2' de iken 2. rejimde kalma olasılı̆̆ı yaklaşık \%67; rejim 3'te iken 3. rejimde kalma olasılığının ise yaklaşık \%72 olduğu görülmektedir. Rejim 1'deyken rejim 2'ye geçme olasılığı oldukça düşük iken rejim 2'den rejim 1'e geçme olasılığ ise yaklaşı \%0,6'dır. Aynı şekilde rejim 1'den rejim 3'e geçme olasılığı yaklaşık \%6 iken, rejim 3'ten rejim 1'e geçme olasılığ 1 ise yaklaşık \%2,7'dir. Rejim 2'den, rejim 3'e geçme olasılığ $1 \% 32,5$ iken rejim 3'ten rejim 2'ye geçme olasılığ $\% 25,4^{\prime}$ tür.

Tablo 9.Rejim Özellikleri

\begin{tabular}{|l|c|c|c|}
\hline & Gözlem & Gün Sayıs & Yüzde \\
\hline Rejim 1 & 371 & 16,68 & $23,50 \%$ \\
\hline Rejim 2 & 524 & 3,02 & $33,19 \%$ \\
\hline Rejim 3 & 684 & 3,55 & $43,32 \%$ \\
\hline
\end{tabular}

Tablo 9'da rejim özellikleri görülmekte olup, BTC serisinin rejim 1'de ortalama kalması süresi 16,68 gün, rejim 2' de ortalama kalma süresi 3,02, rejim üçte ortalama kalma süresi ise 3,55 gün olarak hesaplanmıştır. Bununla birlikte çalışmanın 1.579 günlük periyodu içinde yaklaşık 371 gün rejim 1'de, 524 gün rejim 2'de 684 gün ise rejim 3'te kalındığ 1 tespit edilmiştir. 


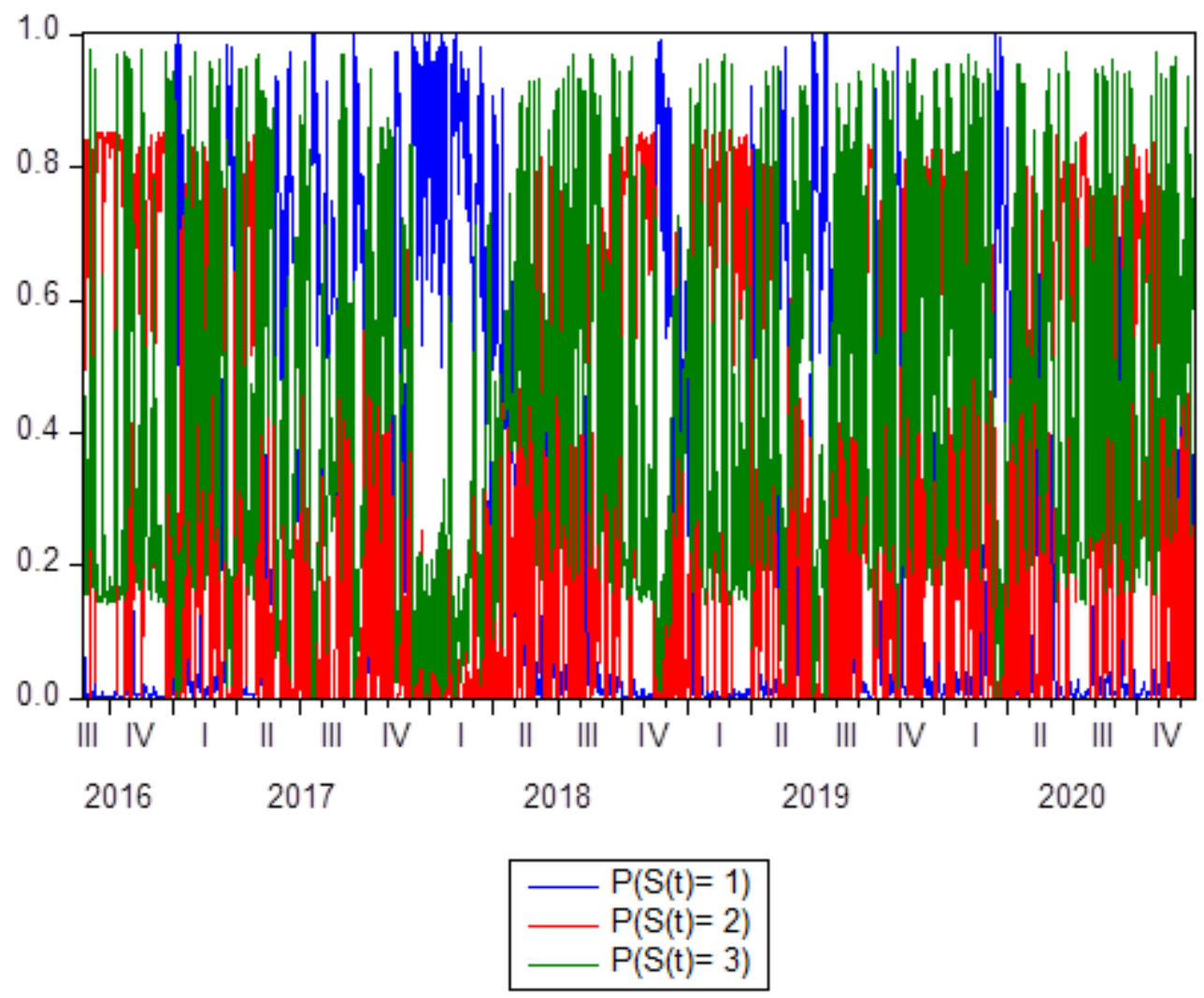

Şekil 2. MS Modelinin Düzgünleştirilmiş Geçiş Olasılıkları (Birleştirilmiş Grafik)

$P(S(t)=1)$

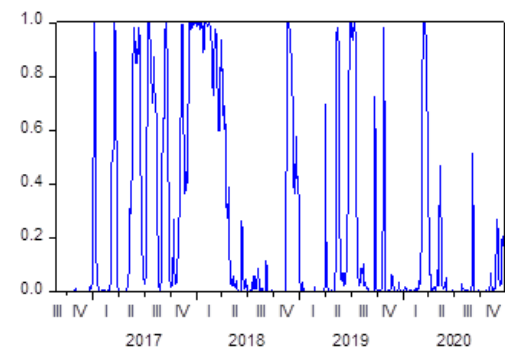

$P(S(t)=2)$

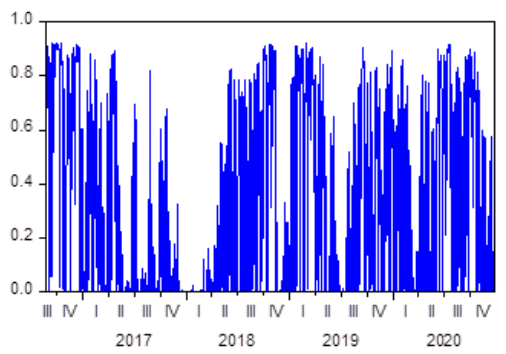

$\mathrm{P}(\mathrm{S}(\mathrm{t})=3)$

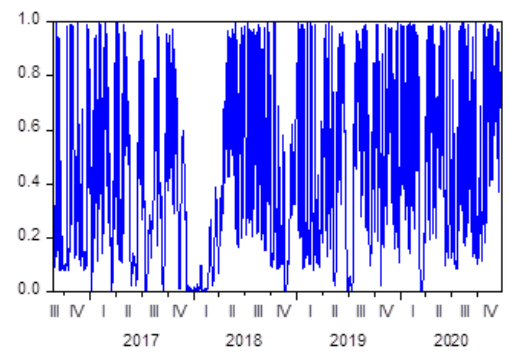

Şekil 3.MS Modelinin Düzgünleştirilmiş Geçiş Olasılıkları (Ayrı Grafikler)

Şekil 2 ve 3'te MSIH(3)-AR(1) modelinin düzgünleştirilmiş rejim olasılıkları verilmiştir. Şekillerde birinci rejimin açıkça diğer rejimlerden ayrıldığı açıkça görülmektedir. Bununla birlikte rejim değişimlerinin bazen birkaç günü kapsayacak şekilde kısa süreler içinde olduğu tespit edilmiştir. Özellikle 2018 yılından itibaren Bitcoin getirilerinin arttığı yaygın olarak ikinci ve üçüncü rejimde olduğu görülmektedir. Bu da her ne kadar volatilitesi yüksek olsa da Bitcoinin yatırımcılar tarafından talep edilen ve getirisi artan bir yatırım aracı haline geldiğini göstermektedir. Bununla birlikte özellikle pandeminin yaratı̆̆ ekonomik daralma ve belirsizlikle birlikte birçok yatırım aracının getirilerinde bir daralmanın yaşanması söz konusu olduğu 2020 yılı itibariyle Bitcoinin getirisinin geçiş ve yükseliş rejiminde olması, pandemi döneminde de bitcoinin tercih edilen önemli ve popüler bir yatırım aracı olduğunu göstermektedir. .

\section{SONUÇ ve TARTIŞMA}

Günümüz finansal piyasalarında yatırımcıların ellerindeki fonları değerlendirme imkanları hem hızlanmış hem de kolaylaşmıştır. Küreselleşmeyle birlikte artan yatırım olanakları yatırımcılarının önüne birçok yatırım alternatifini ortaya koymaktadır. Bu bağlamda yatırım yapmak kolaylaşmış olsa da artan yatırım alternatifleri arasından seçim yapmak daha fazla uğraş isteyen bir alan haline gelmiştir. Teknolojideki hızlı değişimler, yeni finansal enstrüman arayışları, yaşanan ekonomik ve finansal krizler ve son olarak pandeminin gerek reel 
piyasalar gerekse finansal piyasalarda yarattığı etkiler ve merkezi otoriteye olan güvenin azalma eğilimi gibi birçok faktör yatırım alternatifleri arasında kripto paraların cazibesinin artmasına neden olmuştur. Şüphesiz son yıllarda en fazla takip edilen yatıım araçları arasında olan kripto paraların 2020 yılının Aralık ayı itibariyle 8.105 adede ulaşmasına rağmen halen piyasa kapitülasyonunun \%69,1'ini oluşturan Bitcoin en popüler kripto paradır.

Kripto para piyasasının öncü ve en önemli aracı olan Bitcoin'in bir yatırım aracı olarak getirilerinin daralma, geçiş ve yükseliş dönemlerinin bilinmesi hem yatırımcılar hem de finansal piyasalar için getiri öngörülebilirliği açısından önemlidir. Çalışma kapsamında Bitcoin'in yüksek veya düşük getirili dönemlerde kalma, kazandıra, kaybettiren veya geçiş dönemlerine geçme olasılıkları ve bu dönemlerde kalma süreleri MS$\mathrm{AR}(\mathrm{p})$ modelleri ile incelenmiştir.

Çalışma kapsamında çalışmaya konu periyotta Bitcoin getiri serisi için en uygun modelin üç rejimli MSIH(3)AR(1) modeli olduğu tespit edilmiştir. Modele ilişkin analizler yapıldığında ise söz konusu modelin doğrusal modele göre daha güçlü sonuçlar verdiği görülmektedir. Üç rejimden oluşan modelde katsayısı negatif olan rejim 1 daralma rejimi dönemini, katsayıları pozitif olan rejim 2 geçiş ve rejim 3 ise genişleme rejimi dönemini göstermektedir.

Analiz sonuçlarına göre Bitcoin getiri serisinin rejim 1'deyken tekrardan 1. rejimde kalma olasılığı yaklaşık \%94; rejim 2'de iken 2. rejimde kalma olasılığı yaklaşık \%67; rejim 3'te iken 3. rejimde kalma olasılı̆̆ının ise yaklaşık \%72 olduğu görülmektedir. Rejim 1'deyken rejim 2'ye geçiş olasılığı oldukça düşük iken rejim 2'den rejim 1'e geçiş olasılığ 1 ise yaklaşık \%0,6'dır. Aynı şekilde rejim 1'den rejim 3'e geçiş olasılı̆̆1 yaklaşık \%6 iken, rejim 3'ten rejim 1'e geçiş olasılı̆̆ ise yaklaşık \%2,7'dir. Rejim 2'den, rejim 3'e geçiş olasılığ1 \%32,5 iken rejim 3'ten rejim 2'ye geçiş olasılığ $1 \% 25,4^{\prime}$ tür. Bununla birlikte rejim özellikleri görülmekte olup, BTC serisinin rejim 1'de ortalama kalması süresi 16,68 gün, rejim 2'de ortalama kalma süresi 3,02, rejim üçte ortalama kalma süresi ise 3,55 gün olarak hesaplanmıştır. Bununla birlikte çalışmanın 1.579 günlük periyodu içinde yaklaşık 371 gün rejim 1'de, 524 gün rejim 2' de 684 gün ise rejim 3'te kalındığ 1 tespit edilmiştir.

Birinci rejimin bir dönem sonra aynı rejimde kalma olasılığının oldukça yüksek olması, modelde birinci rejimle diğer rejimlerin birbirinden net bir şekilde ayrıldığını göstermektedir. Bu da Bitcoin getirilerinin düşüş dönemlerindeyken bir sonraki dönemde düşüş eğilimi sürdügünü, düşüş rejimindeyken yükseliş rejimleri geçme olasılığının düşük olduğunu göstermekte ve Bitcoin getirilerinin rejim kalıcılığının yüksek olduğunu ortaya koymaktadır. Bu bağlamda yatırımcının, Bitcoin getirilerinin cari dönemde hangi rejimde olduğunu bilmesi halinde, bu rejimde kalma olasılığını tahmin ederek yatırım kararını buna göre verme imkanı bulunmaktadır. Bununla birlikte ortalama rejimlerde kalma sürelerinin düşük olduğu göz önüne alındığında özellikle Bitcoin'i portföylerinde bulunduran aktif yatırımcıların sürekli olarak bu aracın rejim değişimlerini takip etmesi durumunda portföylerinin faydasını arttırma imkanı yakalayacağı görülmektedir.

Çalışma bulgular açısından değerlendirildiğinde, çalışmanın her ne kadar rejim sayıları farklılık gösterse de Moln'ar ve Thies (2018), Chappell (2018), Maupin (2019), Ardia vd (2019), Söylemez ve Yılmaz Türkmen (2019) Mba ve Mwambi (2020), Ma vd. (2020) ve Koki vd.'nin (2020) çalışmalarına paralel olarak en az bir negatif katsayılı yani düşüş rejimi ve yine en az bir pozitif katsayılı yani yükseliş rejimi olduğu ve doğrusal olmayan Markov Rejim modelinin, tek rejimli klasik modele göre daha güçlü sonuçlar verdiği görülmektedir. Bununla birlikte Bitcoin getirilerinin rejim yapısı ve rejim değişiklikleri değerlendirildiğinde; hem tek rejimli modele göre Markov Rejim Değişim modelinin daha güçlü sonuçlar vermesi hem de bir rejimdeyken bir sonraki dönemde tekrar aynı rejimde kalma olasılıklarının yüksek olması, diğer rejime geçme olasılıklarının ise düşük olması açısından Ardia vd. (2018), Söylemez ve Yılmaz Türkmen (2019) ve Rojas ve Coronado (2020)'nun çalışmalarıyla uyumlu sonuçlar verdiği tespit edilmiştir. Çalışma kapsamında Bitcoin getirilerinin kazandıran ve kaybettiren rejimleri, rejim geçiş olasılıkları ve bu rejimde kalma süreleri tespit edilmiştir. Fakat bu rejim değişimine etki eden faktörler ve bunların etki derecelerinin ne olduğu konusu çalışma kapsamı dişında bırakılmıştır. Bu nedenle ilerideki çalışmalarda bu rejimlerin değişim nedenleri ve bu nedenlerin etki derecelerinin tespit edilmesi yatırımcıların rejim değişikliğine etki edecek faktörlere ilişkin beklentilerine göre portföy seçimlerine katkı sağlayacaktır. 


\section{KAYNAKÇA}

Ardia, D., Bluteau, K. and Rüede, M. (2019). Regime Changes in Bitcoin GARCH Volatility Dynamics, Finance Research Letter, 29, 266-271

Bayat, T., Kayhan, S. ve Koçyiğit, A. (2013). Türkiye'de İşsizliğin Asimetrik Davranışının Rejim Değişim Modeliyle İncelenmesi, Business and Economics Research Journal, V. 4, N. 2, pp.79-90

Brock, W., Dechert, W., and Scheinkman, J. (1987). A Test For Independence Based On The Correlation Dimension. Working Paper, University of Wisconsin at Madison, University of Houston and University of Chicago.

Chappell, D., (2018). Regime Heteroskedasticity in Bitcoin: A Comparison of Markov Switching Models, MPRA Paper 90682, University Library of Munich, Germany.

Chen, S.S. (2006), Revisiting the Interest Rate-Exchange Rate Nexus: A Markov- Switching Approach, Journal of Development Economics, Vol. 79, pp. 208-224.

Dadaloğlu, C. (2018). Ekonomik Yatırım Araçları Getirilerinin Saklı Markov Modeli ile Tahmin Edilmesi: Türkiye Örneği (Yüksek lisans tezi). Çukurova Üniversitesi Sosyal Bilimler Enstitüsü, Adana.

Davies, R. B., Harte, D. S. (1978), Hypothesis Testing When the Nuisance Parameter is Present Only Under The Alternative. Biometrica, 74, pp. 33-43.

Diebold, F.X., Lee, J.H. and Weinbach, G.C. (1994). Regime Switching With Time-Varying Transition Probabilities. In C. Hargreaves (ed.) Nonstationary Time Series Analysis and Cointegration, 283-302, Oxford: Oxford University Press.

Engel, C. (1994). Can The Markov-Switching Model Forecast Exchange Rates. Journal of International Economics, 36, 151-165.

Eroğlu, A. (2019). Yöneylem Araştırması, İstanbul Üniversitesi Açık ve Uzaktan Eğitim Fakültesi Yayınları

Evci, S. (2020). Bitcoin Piyasasında Haftanın Günü Anomalisi, Alanya Akademik Bakış, 4(1), 53-61

Evci, S., Şak, N. ve Adana Karaağaç, G. (2016). Altın Fiyatlarındaki Değiş̧imin Markov Rejim Değişim Modelleriyle İncelenmesi, Business and Economics Research Journal, V.7, N.4, 66-77

Güleşce, A. (2019). Faiz Oranı Öngörüsü için Markov Değişim Modeli (Yüksek lisans tezi). Marmara Üniversitesi Sosyal Bilimler Enstitüsü, İstanbul.

Gültekin, Y. , Bulut, Y . (2016). Bitcoin Ekonomisi: Bitcoin Eko-Sisteminden Doğan Yeni Sektörler ve Analizi. Adnan Menderes Üniversitesi Sosyal Bilimler Enstitüsü Dergisi , 3 (3) , 82-92

Hamilton, J. D. (1989). A New Approach to The Economic Analysis of Nonstationary Time Series and the Business Cycle. Econometrica, Vol: 57, No. 2, 357-384.

Hamilton, J. D. (1996). Spesification Testing in Markov-Switching Time Series Models. Journal of Econometrics, Vol:70, No.1, 127-157.

https://coinmarketcap.com/

https//www. investing.com

Kim, C.J. ve Nelson, G. (1998) State-Space Models with Regime-Switching: Classical and Gibbs -Sampling Approaches with Application, MIT Press.

Koki, C., Leonardos, S. and Piliouras, G. (2020). Exploring the Predictability of Cryptocurrencies via Bayesian Hidden Markov Models, Papers 2011.03741, arXiv.org

Krolzig, H.M. (1997) Markov Switching Vector Autoregressions. Modelling, Statistical Inference and Application to Business Cycle Analysis, Berlin: Springer.

Krolzig, H.M. (2001) Estimation, Structural Analysis and Forecasting of RegimeSwitching Model With MSVAR for Ox, Oxford University Press. 
M. C. Samırkaş 13/1 (2021) 813-824

Krolzig, H.M. (1988) Impulse-Response Analysis in Markov Switching Vector Autoregressive Models, Economics Department, University of Kent College, Canterbury City

Krolzig, H.M. (1998) Econometric Modelling of Markov-Switching Vector Autoregressions Using MS-VAR For Ox, Oxford University Press.

Krolzig, H.M. (2000) Predicting Markov-Switching Vector Autoregressive Processes. Oxford University Working Paper no. 2000w31.

Ma, F., Lang, C., Ma, Y. and Wahab, M.I.M. (2020). Cryptocurrency Volatility Forecasting: a Markov Regimeswitching MIDAS Approach. Journal of Forecasting. 39:1277-1290.

Maupin, T. (2019). Can Bitcoin, and Other Cryptocurrencies, be Modeled Effectively with a Markov-Switching Approach?. (Degree Project) Royal Institute of Technology School of Engineering Sciences, Stocholm, Sweden

Mba, J.C. and Mwambi, S. (2020). A Markov-Switching COGARCH Approach to Cryptocurrency Portfolio Selection and Optimization. Financial Markets and Portfolio Management, 34:199-214

Rojas, O., and Coronado, S. (2020). A Bayesian Study of Changes in Volatility Of Bitcoin. Contaduría y Administración, Article in Press, 1-17.

Sezgin Alp, Ö. ve Kırkbeşoğlu, E. (2015). Sigorta Endeksi Getirisinin Doğrusal Olmayan Yapısı, Finansal Araştırmalar ve Çalışmalar Dergisi • Cilt 7 • Sayı 13 • Temmuz 2015, ss. 245-260

Söylemez, Y. ve Yılmaz Türkmen, S. (2019). Bitcoin Volatilitesinin Analizinde Markov Rejim Değişken Karar Destek Modellerinin Kullanılması, 23. Finans Sempozyumu, Marmara Üniversitesi, İstanbul

Thies, S and Moln'ar, P. (2018) Bayesian Change Point Analysis of Bitcoin Returns. Finance Research Letters, December, 223-227 